(2) Open Access Full Text Article

\title{
Improving the Management of Patients with Osteoporosis Undergoing Spinal Fusion: The Need for a Bone Mineral Density-Matched Interbody Cage
}

\author{
Steven M Falowski ${ }^{\prime}$ \\ Sebastian F Koga $\mathbb{D}^{2}$ \\ Trent Northcutt ${ }^{3}$ \\ Laszlo Garamszegi ${ }^{3}$ \\ Jeremi Leasure ${ }^{3}$ \\ Jon E Block $\mathbb{D}^{4}$
}

'Argires-Marotti Neurosurgical Associates of Lancaster, Lancaster, PA, USA; ${ }^{2}$ Koga Neurosurgery, Covington, LA, USA; ${ }^{3}$ Aurora Spine, Carlsbad, CA USA; ${ }^{4}$ Independent Clinical Consultant, San Francisco, CA, USA
Correspondence: Jon E Block

Independent Clinical Consultant, 2210

Jackson Street, Ste. 40I, San Francisco,

CA, 94II5, USA

Tel + I 4I5-775-7947

Email jb@drjonblock.com

\begin{abstract}
With an increasingly aging population globally, a confluence has emerged between the rising prevalence of degenerative spinal disease and osteoporosis. Fusion of the anterior spinal column remains the mainstay surgical intervention for many spinal degenerative disorders. However, decreased vertebral bone mineral density (BMD), quantitatively measured by dual $\mathrm{x}$-ray absorptiometry (DXA), complicates treatment with surgical interbody fusion as weak underlying bone stock increases the risk of post-operative implant-related adverse events, including cage subsidence. There is a necessity for developing cages with advanced structural designs that incorporate bioengineering and architectural principles to tailor the interbody fusion device directly to the patient's BMD status. Specifically, lattice-designed cages that mimic the web-like structure of native cancellous bone have demonstrated excellent resistance to postoperative subsidence. This article provides an introductory profile of a spinal interbody implant designed intentionally to simulate the lattice structure of human cancellous bone, with a similar modulus of elasticity, and specialized to match a patient's bone status across the BMD continuum. The implant incorporates an open pore design where the degree of pore compactness directly corresponds to the patient's DXA-defined BMD status, including patients with osteoporosis.
\end{abstract}

Keywords: osteoporosis, interbody fusion, bone mineral, cage, degenerative disc disease

\section{Introduction}

Orthograde human posture, with the adaptation of a curved and flexible spine, places high axial compressive loads across the spinal joint complex resulting in nearly universal evidence of arthritic deterioration among older adults. ${ }^{1-5}$ When age-related spondylosis leads to neural compression and chronic pain, instrumented fusion of the anterior spinal column remains one of the preferred surgical interventions. $^{6-9}$

Following discectomy, an interbody fusion device or cage is typically employed to re-establish intervertebral disc space, providing immediate stability and neural decompression with symptom relief. ${ }^{8}$ The cage also serves as a carrier for bone graft, stimulating osseointegration to facilitate endplate-to-endplate arthrodesis. ${ }^{10}$

Set against the backdrop of an increasingly aging population, this paper elucidates the confluence between the rising prevalence of both degenerative disc disease and osteoporosis. Specifically, we highlight the necessity of developing 
cages with advanced structural designs that incorporate bioengineering and architectural principles to tailor the interbody fusion device directly to the patient's bone mineral density (BMD) status as commonly diagnosed by dual x-ray absorptiometry (DXA, or colloquially "DEXA").

\section{The Aging of the Population}

The "greying" of the US population is a well-established demographic phenomenon that has generated significant interest in developing medical programs and health care policy initiatives specifically targeted to advance knowledge of and plan investments for the elderly. At the root of this phenomenon are the combined effects of plunging birth rates and increased longevity. ${ }^{11}$ In fact, in the US, the expansion of the older population will continue unabated for many decades to come, primarily fueled by the aging of the baby boom cohort. With the 65 and over age cohort projected to encompass 95 million or $23 \%$ of the population by 2060, North America remains the second oldest region globally.

With the exception of the African continent where high fertility rates persist, the demographics of the remainder of the world mirror the rapid expansion of the older population experienced in the US. ${ }^{12}$ Worldwide in 2015, approximately $9 \%$ of the population was $\geq 65$ years old. This global estimate is projected to swell to $12 \%$ by 2030 , with almost 1 in 6 individuals (17\%) being 65 years or older by 2050 .

\section{Epidemiology of Degenerative Disc Disease and Surgical Treatment with Interbody Fusion}

Degeneration of the intervertebral disc represents the initial pathoanatomical stage of degenerative spinal changes, ${ }^{13}$ which gradually progresses to involve deterioration of associated osteo-ligamentous structures, such as the facet joints, and stenosis of the central and foraminal canals. ${ }^{14}$ Starting as early as the fourth decade of life, degeneration of the intervertebral disc occurs commonly. Undertaking a systematic review of 20 studies, Battie et $\mathrm{al}^{15}$ were the first to estimate the prevalence of disc degeneration based on magnetic resonance imaging (MRI) evaluations of asymptomatic individuals. Prevalence rates for disc abnormalities at any vertebral level ranged from $3 \%$ to $56 \%$ for disc narrowing, $6 \%$ to $56 \%$ for disc tears, $10 \%$ to $81 \%$ for disc bulges, $3 \%$ to
$63 \%$ for disc protrusions, and $20 \%$ to $83 \%$ for MRI signal intensity reduction. ${ }^{16}$

Using MRI that encompassed the entire spinal column, Teraguchi et al ${ }^{17}$ reported the occurrence of disc degeneration in $71 \%$ of men and $77 \%$ of women $\leq$ age 50 years, and $>90 \%$ in both men and women $>$ age 50 years. Employing longitudinal computed tomography (CT) imaging data from 1196 participants in the Framingham study, Jarraya et $\mathrm{al}^{18}$ found that more than one-third of women (ages 40-59) demonstrated moderate-to-severe disc height narrowing, and this prevalence increased 2- to 4-fold with increasing age. Lastly, Ravindra et al ${ }^{19}$ calculated the global incidence of patients with degenerative disc disease coupled with clinical low back pain using the Global Burden of Disease Database (Institute for Health Metrics and Evaluation). Almost $4 \%$ of individuals worldwide, or 266 million individuals, are estimated to have clinically significant symptoms of low back pain resulting from disc disease annually.

Interbody spinal fusion represents a common surgical treatment for patients with chronically-severe back pain, impaired function and reduced quality of life. The Agency for Healthcare Research and Quality (AHRQ) estimated that approximately 488,000 spinal fusion procedures were performed in 2011, accounting for over 3\% of all operating room procedures. ${ }^{20}$ More recently, a 2020 estimate (iData Research) determined that approximately 1.62 million instrumented spinal fusion procedures were performed annually including 352,000 interbody procedures involving cages.

To address this enormous patient population, dozens of commercial entities worldwide have developed interbody cage devices of various sizes, styles, shapes, and materials including titanium, polyether ether ketone (PEEK), ceramic, carbon fiber as well as cortical allograft dowels and spacers. ${ }^{21}$ Commercially-available devices include both static and lowprofile expandable cages. Following surgical disc removal, intervertebral cages are inserted from an anterior approach in the cervical spine, and anterior, posterior, oblique, and lateral approaches in the lumbar spine. The common purpose of all cages is to provide intervertebral distraction and neural decompression until solid fusion occurs. Supplementary fixation with pedicle screws and posterior instrumentation is often required to provide a stable construct for fusion to take place.

\section{Prevalence of Osteoporosis}

Osteoporosis is the most common bone disorder, affecting over 200 million people globally and representing a public health epidemic. ${ }^{22}$ As an age-related medical condition, low BMD, commonly referred to as osteopenia, and 
osteoporosis, the most severe manifestation of low BMD, are being more frequently diagnosed by non-invasive imaging technologies such as DXA among the ever-expanding elderly population. While significantly increasing the risk of vertebral compression fractures, this condition occurs pari passu with the development of arthritic degenerative changes described previously. The confluence of these syndromes creates a more challenging and complex interventional strategy for the spine surgeon contemplating interbody fusion. $^{23}$

A patient with osteoporosis is characterized as having a BMD T-score of $\leq-2.5$ standard deviations below the comparative reference value for a young gender-matched population at peak bone mass. ${ }^{24,25}$ Osteopenia is the range of bone loss between normal BMD and osteoporosis (ie, T-score; $<-1.0->-2.5$ ). Measurement of BMD is accomplished most commonly using DXA and, less frequently, with quantitative computed tomography (qCT). ${ }^{24}$ It has been estimated that approximately $45-50 \%$ of US adults have low BMD with 10-15\% suffering from definitive osteoporosis as per current definitional standards. ${ }^{26-28}$ Based on 2010 worldwide statistics, almost 160 million individuals had increased fracture risk due to low BMD and this prevalence is expected to balloon to 300 million at risk individuals by $2040 .^{29}$

\section{Interbody Fusion in the Presence of Osteoporosis}

Underlying low BMD has been associated with serious postoperative, device-related adverse events such as implant subsidence, ${ }^{30-36}$ pedicle screw loosening, ${ }^{37,38}$ subsequent adjacent-level fractures, ${ }^{39,40}$ and the need for revision surgery. ${ }^{41}$ Clinically-significant implant subsidence occurs in about $10 \%$ of cases, ${ }^{42}$ precipitating spinal instability and recurrence of neuro-compressive symptoms, ${ }^{34,35}$ particularly among older individuals with spinal osteoporosis. ${ }^{43,44}$
Historically, a diagnosis of definitive osteoporosis has often been considered a contraindication to spinal fusion due to weak vertebral bone stock. ${ }^{45,46}$

It is therefore impossible to exclude all at-risk patients from spinal surgery. Estimates of the proportion of patients undergoing spinal fusion procedures with undiagnosed osteoporosis have ranged from $17 \%$ to $31 \%$. $^{47,48}$ These figures underscore the need to develop specialized techniques, procedures and implants to address this growing patient population so they may experience symptom relief and clinical benefit from surgery.

\section{Evolution of Bioactive Interbody Fusion Devices}

Spinal interbody devices have traditionally been used in a supportive role for static anatomical correction by reestablishing disc space height to provide indirect decompression, and restoring sagittal alignment by inducing lordosis. ${ }^{6,49-51}$ Newer model devices have also introduced bone windows to act as carriers of osteopromotive bone graft. ${ }^{52}$ Despite hundreds of cage types being cleared for commercial use in the US, ${ }^{53}$ only recently has there emerged an appreciation of the possible contribution interbody implants may play in the fusion consolidation process. Figure 1 illustrates the evolution of interbody cage designs and materials.

Bioactive or biokinetic implants are currently being designed that maximize and optimize cage topology and microstructure to reduce the risks, such as subsidence, associated with implantation in a low BMD or osteoporotic environment. ${ }^{54-59}$ Specifically, lattice-designed cages that mimic the web-like structure of native cancellous bone have demonstrated excellent resistance to postoperative subsidence. $^{60-62}$

\section{Evolution of Interbody (cervical spine) cage materials:}

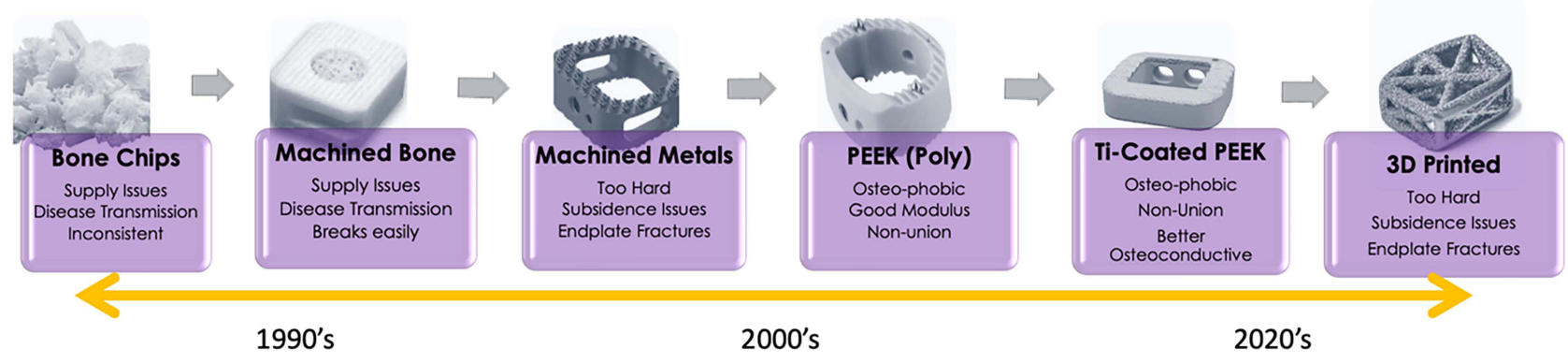

Figure I Evolutionary time line of spinal interbody fusion device types and materials. 


\section{Development of a BMD-Specific Interbody Cage Device}

This article provides an introductory profile of a spinal interbody implant designed intentionally to simulate the lattice structure of human cancellous bone, with a similar modulus of elasticity, and specialized to match a patient's bone status across the BMD continuum (DEXA TiBone ${ }^{\mathrm{TM}}$, Aurora Spine, Carlsbad, Ca USA). Indeed, native vertebral bone trabeculae orient spatially in response to the direction of axial compressive forces, ${ }^{63}$ forming a web-like structure of cancellous bone with exceptionally high load-bearing capacity. ${ }^{64}$ The implant has an open, porous structure that supports osseointegration and vascularization (Figure 2).

The implant is optimized for size to allow maximal contact with the apophyseal ring, and also incorporates a textured surface modification. There is a large body of evidence to demonstrate that introducing a roughened surface topography elicits a bone stimulatory effect with increased bony ongrowth. ${ }^{65-70}$ New bone matrix interdigitates within the crevices and asperities on the roughened surface to form a secure bond at the bone-implant interface. ${ }^{69}$

By modulating the density and compactness of the pore structure, this device can be configured to match a patient's BMD T-score, with cages available to support patients across the BMD spectrum, including those with osteoporosis (Figure 3). Three designs are available reflecting low, mid and high-density BMD T-scores as classified by DXA.

This spinal interbody device has undergone a series of bench-top biomechanical testing procedures in accordance with standardized methods and protocols (ASTM F2077, Test Methods for Intervertebral Body Fusion Devices). Testing included measurements of static axial compression, static torsion/torque, static compression-shear, dynamic compression, and dynamic torsion/torque in six implants. In addition to the DEXA TiBone ${ }^{\mathrm{TM}}$ implant, all tests were conducted with six predicate spinal interbody implants composed of polyetheretherketone (PEEK) (DISCOVERYTM, Aurora Spine, Carlsbad, CA USA). Mean values between groups were compared using the two-sample $t$-test (2-tailed).

We observed an $87 \%$ and $88 \%$ improvement in favor of the DEXA implant for static compression yield load (22.4 \pm 7.1 vs $12.0 \pm 0.1 \mathrm{kN}, \mathrm{p}=0.005)$ and static compression-shear yield load $(12.2 \pm 0.4$ vs $6.5 \pm 0.1 \mathrm{kN}, \mathrm{p}=0.0001)$, respectively. There was also a robust statistical difference $(p=0.0001)$ in static torque yield moment between implants; DEXA $(51.8 \pm 2.3 \mathrm{Nm})$, PEEK $(7.05 \pm 0.38 \mathrm{Nm})$. For dynamic tests run out to 5 million cycles, we found an equivalent endurance limit between implants in compression ( $3.0 \mathrm{vs} 4.0 \mathrm{kN}, \mathrm{p}=0.10$ ) and double the torsional strength for the DEXA implant ( 4.0 vs $2.0 \mathrm{Nm}, \mathrm{p}=0.01$ ).

The DEXA TiBone ${ }^{\mathrm{TM}}$ spinal interbody implant received $510(\mathrm{k})$ premarket notification for commercial use in the US in 2021 (DEXA-C Cervical Interbody System, K210521).

\section{Conclusions}

Current projections indicate a continued upward trajectory in the prevalence of patients afflicted with spinal degenerative disorders with concomitant osteoporosis that require interbody fusion procedures. Traditionally, cage devices for spinal fusion procedures have been "one size fits all" without any architectural or topological modifications to account for variations in the underlying vertebral BMD, including osteoporotic bone. Spinal fusion patients present with a range of vertebral BMD, but most commercially-available implants have a significantly higher density and are more rigid than the supporting bony structures. We introduce a new spinal interbody fusion device with a unique biomechanical profile that is bone densityspecific and may be used in patients with osteoporotic
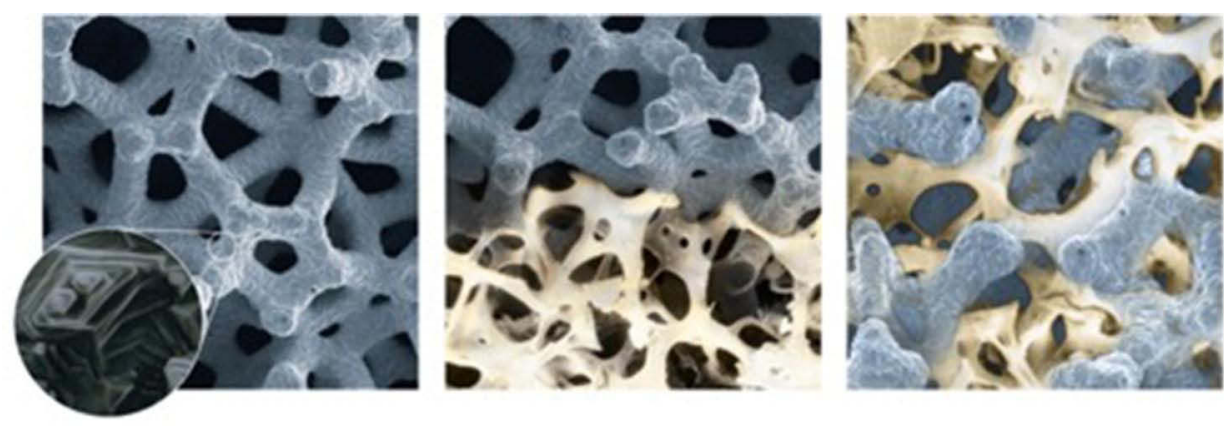

Figure 2 Rendering illustrating an open pore structure of the DEXA TiBone ${ }^{\mathrm{TM}}$ interbody implant at the macro-level (mm) showing hypothetical progression of osseointegration and vascularization throughout the implant (left to right). Inset image (far left) illustrates the roughened titanium surface modifications at the micron level. 


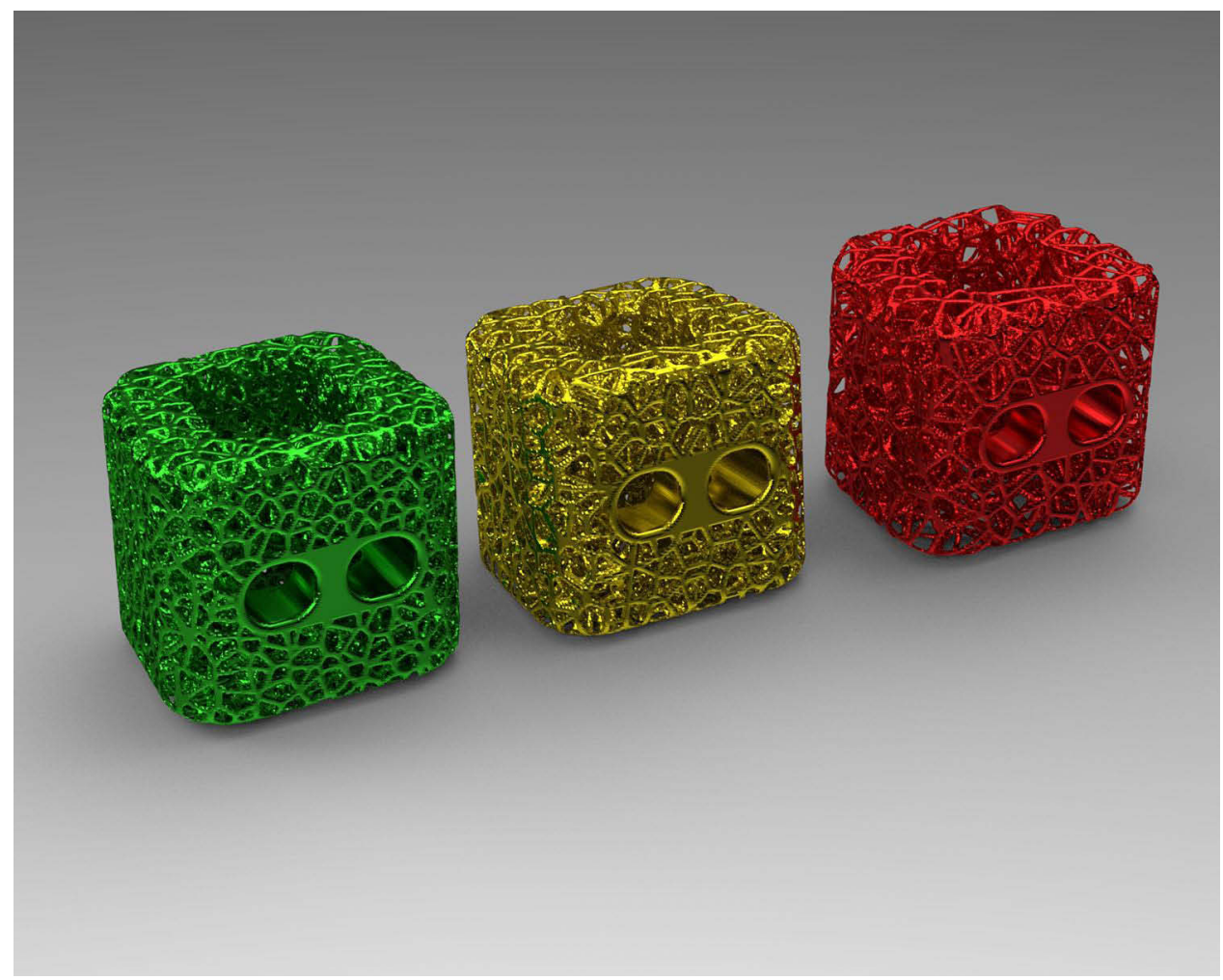

Figure 3 BMD-specific cervical interbody fusion devices showing high (green), mid (yellow) and low (red) density patient-matched implants (Aurora Spine, Carlsbad, CA USA).

bone. Further research into the clinical utility of these design features is encouraged.

\section{Data Sharing Statement}

Requests for data sharing can be made by contacting the corresponding author. Individual participant data that underlie the results reported in this article will be made available (after deidentification) from 9 to 36 months after article publication. Data sharing will be limited to investigators whose proposed use of the data has been approved by an independent review committee identified for this purpose.

\section{Acknowledgments}

Financial support for this work was provided by Aurora Spine (Carlsbad, Ca, USA).

\section{Author Contributions}

All authors made a significant contribution to the work reported, whether that is in the conception, study design, execution, acquisition of data, analysis and interpretation, or in all these areas; took part in drafting, revising or critically reviewing the article; gave final approval of the version to be published; have agreed on the journal to which the article has been submitted; and agree to be accountable for all aspects of the work.

\section{Disclosure}

SMF reports personal fees for research, equity, and/or investment from Aurora, CornerLoc, PainTeq, SPR Therapeutics, Vertiflex, Abbott, Medtronic, Saluda, Vertos, SurgenTec, Mainstay, Relievant, Thermaquil, and SpineThera. He also reports ownership of Celery and Neural Integrative Solutions, outside the submitted work. SFK reports a preliminary patent pending to Spine Corpectomy Cage. TN, LG, and JL are employees of Aurora Spine. LG reports a patent $(10,779,954)$ issued to Aurora Spine, Inc. JEB is an independent advisor to Aurora Spine and was remunerated for assistance in manuscript development. The authors report no other conflicts of interest in this work.

\section{References}

1. Stefanakis M, Luo J, Pollintine P, Dolan P, Adams MA. ISSLS prize winner: mechanical influences in progressive intervertebral disc degeneration. Spine. 2014;39(17):1365-1372. doi:10.1097/BRS.0000000 000000389 
2. Pennisi E. Evolutionary biology. The burdens of being a biped. Science. 2012;336(6084):974. doi:10.1126/science.336.6084.974

3. Filler AG. Emergence and optimization of upright posture among hominiform hominoids and the evolutionary pathophysiology of back pain. Neurosurg Focus. 2007;23(1):E4. doi:10.3171/FOC-07/07/E4

4. Latimer B. The perils of being bipedal. Ann Biomed Eng. 2005;33 (1):3-6. doi:10.1007/s10439-005-8957-8

5. Brandt KD, Dieppe P, Radin E. Etiopathogenesis of osteoarthritis. Med Clin North Am. 2009;93(1):1-24, xv. doi:10.1016/j. mcna.2008.08.009

6. Blumenthal SL, Ohnmeiss DD. Nass. Intervertebral cages for degenerative spinal diseases. Spine J. 2003;3(4):301-309. doi:10.1016/ S1529-9430(03)00004-4

7. Eck JC, Sharan A, Ghogawala Z, et al. Guideline update for the performance of fusion procedures for degenerative disease of the lumbar spine. Part 7: lumbar fusion for intractable low-back pain without stenosis or spondylolisthesis. J Neurosurg Spine. 2014;21 (1):42-47. doi:10.3171/2014.4.SPINE14270

8. Mobbs RJ, Phan K, Malham G, Seex K, Rao PJ. Lumbar interbody fusion: techniques, indications and comparison of interbody fusion options including PLIF, TLIF, MI-TLIF, OLIF/ATP, LLIF and ALIF. J Spine Surg. 2015;1(1):2-18. doi:10.3978/j.issn.2414-469X.2015.10.05

9. Mummaneni PV, Dhall SS, Eck JC, et al. Guideline update for the performance of fusion procedures for degenerative disease of the lumbar spine. Part 11: interbody techniques for lumbar fusion. $J$ Neurosurg Spine. 2014;21(1):67-74. doi:10.3171/2014.4.SPINE14276

10. Kaiser MG, Groff MW, Watters WC 3rd, et al. Guideline update for the performance of fusion procedures for degenerative disease of the lumbar spine. Part 16: bone graft extenders and substitutes as an adjunct for lumbar fusion. $J$ Neurosurg Spine. 2014;21(1):106-132. doi:10.3171/2014.4.SPINE14325

11. Roberts AW, Ogunwole SU, Blakeslee L, Rabe MA. The Population 65 and Older in the United States: 2016. Bureau USC ed. American Community Survey Reports; 2018.

12. Robert $\mathrm{L}$. The rapid increase of the aging population worldwide and especially in industrialized countries. Biomed Pharmacother. 2003;57 (5-6):185-186. doi:10.1016/S0753-3322(03)00051-9

13. Boos N, Weissbach S, Rohrbach H, Weiler C, Spratt KF, Nerlich AG. Classification of age-related changes in lumbar intervertebral discs: $<Y>2002$ Volvo Award in basic science. Spine. 2002;27 (23):2631-2644. doi:10.1097/00007632-200212010-00002

14. Ahn TJ, Lee SH, Choi G, et al. Effect of intervertebral disk degeneration on spinal stenosis during magnetic resonance imaging with axial loading. Neurol Med Chir. 2009;49(6):242-247; discussion 247. doi:10.2176/nmc.49.242

15. Battie MC, Videman T, Parent E. Lumbar disc degeneration: epidemiology and genetic influences. Spine. 2004;29(23):2679-2690. doi:10.1097/01.brs.0000146457.83240.eb

16. Donnally IC, Hanna A, Varacallo M. Lumbar Degenerative Disk Disease. StatPearls. Treasure Island (FL); 2020.

17. Teraguchi M, Yoshimura N, Hashizume $\mathrm{H}$, et al. Prevalence and distribution of intervertebral disc degeneration over the entire spine in a population-based cohort: the Wakayama Spine Study. Osteoarthritis Cartilage. 2014;22(1):104-110. doi:10.1016/j. joca.2013.10.019

18. Jarraya M, Guermazi A, Lorbergs AL, et al. A longitudinal study of disc height narrowing and facet joint osteoarthritis at the thoracic and lumbar spine, evaluated by computed tomography: the Framingham Study. Spine J. 2018;18(11):2065-2073. doi:10.1016/j.spinee.2018.04.010

19. Ravindra VM, Senglaub SS, Rattani A, et al. Degenerative lumbar Spine disease: estimating global incidence and worldwide volume. Global Spine J. 2018;8(8):784-794. doi:10.1177/2192568218770769

20. Weiss AJ, Elixhauser A, Andrews RM. Characteristics of Operating Room Procedures in U.S. Hospitals, 2011: statistical Brief \#170. In: Healthcare Cost and Utilization Project (HCUP) Statistical Briefs. Rockville (MD); 2006.
21. Rao PJ, Pelletier MH, Walsh WR, Mobbs RJ. Spine interbody implants: material selection and modification, functionalization and bioactivation of surfaces to improve osseointegration. Orthop Surg. 2014;6(2):81-89. doi:10.1111/os.12098

22. Sozen T, Ozisik L, Basaran NC. An overview and management of osteoporosis. Eur J Rheumatol. 2017;4(1):46-56. doi:10.5152/ eurjrheum. 2016.048

23. Fiani B, Newhouse A, Sarhadi KJ, Arshad M, Soula M, Cathel A. Special considerations to improve outcomes in patients with osteoporosis undergoing spine surgery. Int J Spine Surg. 2021;15 (2):386-401. doi:10.14444/8050

24. Cummings SR, Bates D, Black DM. Clinical use of bone densitometry: scientific review. JAMA. 2002;288(15):1889-1897. doi:10.1001/ jama.288.15.1889

25. Shepherd JA, Blake GM. T-scores and Z-scores. J Clin Densitom. 2007;10(4):349-350. doi:10.1016/j.jocd.2007.08.006

26. Wright NC, Looker AC, Saag KG, et al. The recent prevalence of osteoporosis and low bone mass in the United States based on bone mineral density at the femoral neck or lumbar spine. $J$ Bone Miner Res. 2014;29(11):2520-2526. doi:10.1002/jbmr.2269

27. Looker AC, Borrud LG, Dawson-Hughes B, Shepherd JA, Wright NC. Osteoporosis or low bone mass at the femur neck or lumbar spine in older adults: United States, 2005-2008. NCHS Data Brief. 2012;1(93):1-8.

28. Looker AC, Sarafrazi Isfahani N, Fan B, Shepherd JA. Trends in osteoporosis and low bone mass in older US adults, 2005-2006 through 2013-2014. Osteoporos Int. 2017;28(6):1979-1988. doi:10.1007/s00198-017-3996-1

29. Oden A, McCloskey EV, Kanis JA, Harvey NC, Johansson H. Burden of high fracture probability worldwide: secular increases 2010-2040. Osteoporos Int. 2015;26(9):2243-2248. doi:10.1007/s00198-0153154-6

30. Cho JH, Hwang CJ, Kim H, Joo YS, Lee DH, Lee CS. Effect of osteoporosis on the clinical and radiological outcomes following one-level posterior lumbar interbody fusion. J Orthop Sci. 2018;23 (6):870-877. doi:10.1016/j.jos.2018.06.009

31. DeWald CJ, Stanley T. Instrumentation-related complications of multilevel fusions for adult spinal deformity patients over age 65 : surgical considerations and treatment options in patients with poor bone quality. Spine. 2006;31(19 Suppl):S144-151. doi:10.1097/01. brs.0000236893.65878.39

32. Formby PM, Kang DG, Helgeson MD, Wagner SC. Clinical and Radiographic Outcomes of Transforaminal Lumbar Interbody Fusion in Patients with Osteoporosis. Global Spine J. 2016;6 (7):660-664. doi:10.1055/s-0036-1578804

33. Karikari IO, Jain D, Owens TR, et al. Impact of subsidence on clinical outcomes and radiographic fusion rates in anterior cervical discectomy and fusion: a systematic review. J Spinal Disord Tech. 2014;27(1):1-10. doi:10.1097/BSD.0b013e31825bd26d

34. Lewandrowski KU, Ransom NA, Yeung A. Subsidence induced recurrent radiculopathy after staged two-level standalone endoscopic lumbar interbody fusion with a threaded cylindrical cage: a case report. J Spine Surg. 2020;6(Suppl 1):S286-S293. doi:10.21037/ jss.2019.09.25

35. Rao PJ, Phan K, Giang G, Maharaj MM, Phan S, Mobbs RJ. Subsidence following anterior lumbar interbody fusion (ALIF): a prospective study. $J$ Spine Surg. 2017;3(2):168-175. doi:10.21037/jss.2017.05.03

36. Xi Z, Mummaneni PV, Wang M, et al. The association between lower Hounsfield units on computed tomography and cage subsidence after lateral lumbar interbody fusion. Neurosurg Focus. 2020;49(2):E8. doi: $10.3171 / 2020.5$.FOCUS20169

37. Bredow J, Boese CK, Werner CM, et al. Predictive validity of preoperative CT scans and the risk of pedicle screw loosening in spinal surgery. Arch Orthop Trauma Surg. 2016;136(8):1063-1067. doi:10.1007/s00402-016-2487-8 
38. Halvorson TL, Kelley L, Thomas KA, Whitecloud TS 3rd, Cook SD. Effects of bone mineral density on pedicle screw fixation. Spine. 1994;19(21):2415-2420. doi:10.1097/00007632-199411000-00008

39. Meredith DS, Schreiber JJ, Taher F, Cammisa FP Jr, Girardi FP. Lower preoperative Hounsfield unit measurements are associated with adjacent segment fracture after spinal fusion. Spine. 2013;38 (5):415-418. doi:10.1097/BRS.0b013e31826ff084

40. Toyone T, Ozawa T, Kamikawa K, et al. Subsequent vertebral fractures following spinal fusion surgery for degenerative lumbar disease: a mean ten-year follow-up. Spine. 2010;35(21):1915-1918. doi:10.1097/BRS.0b013e3181dc846c

41. Gupta A, Cha T, Schwab J, et al. Osteoporosis increases the likelihood of revision surgery following a long spinal fusion for adult spinal deformity. Spine J. 2021;21(1):134-140. doi:10.1016/j. spinee.2020.08.002

42. Macki M, Anand SK, Surapaneni A, Park P, Chang V. Subsidence Rates After Lateral Lumbar Interbody Fusion: a Systematic Review. World Neurosurg. 2019;122:599-606. doi:10.1016/j.wneu.2018. 11.121

43. Okano I, Jones C, Salzmann SN, et al. Postoperative decrease of regional volumetric bone mineral density measured by quantitative computed tomography after lumbar fusion surgery in adjacent vertebrae. Osteoporos Int. 2020;31(6):1163-1171. doi:10.1007/ s00198-020-05367-3

44. Okano I, Jones C, Salzmann SN, et al. Endplate volumetric bone mineral density measured by quantitative computed tomography as a novel predictive measure of severe cage subsidence after standalone lateral lumbar fusion. Eur Spine J. 2020;29(5):1131-1140. doi:10.1007/s00586-020-06348-0

45. Tome-Bermejo F, Pinera AR, Alvarez L. Osteoporosis and the Management of Spinal Degenerative Disease (II). Arch Bone $J t$ Surg. 2017;5(6):363-374.

46. Tome-Bermejo F, Pinera AR, Alvarez-Galovich L. Osteoporosis and the Management of Spinal Degenerative Disease (I). Arch Bone $J t$ Surg. 2017;5(5):272-282.

47. Chin DK, Park JY, Yoon YS, et al. Prevalence of osteoporosis in patients requiring spine surgery: incidence and significance of osteoporosis in spine disease. Osteoporos Int. 2007;18(9):1219-1224. doi:10.1007/s00198-007-0370-8

48. Wagner SC, Formby PM, Helgeson MD, Kang DG. Diagnosing the Undiagnosed: osteoporosis in Patients Undergoing Lumbar Fusion. Spine. 2016;41(21):E1279-E1283. doi:10.1097/BRS.0000000000 001612

49. Barrey C, Darnis A. Current strategies for the restoration of adequate lordosis during lumbar fusion. World J Orthop. 2015;6(1):117-126.

50. Godde S, Fritsch E, Dienst M, Kohn D. Influence of cage geometry on sagittal alignment in instrumented posterior lumbar interbody fusion. Spine. 2003;28(15):1693-1699. doi:10.1097/01.BRS.0000 083167.78853.D5

51. Kim JT, Shin MH, Lee HJ, Choi DY. Restoration of lumbopelvic sagittal alignment and its maintenance following transforaminal lumbar interbody fusion (TLIF): comparison between straight type versus curvilinear type cage. Eur Spine J. 2015;24:2588-2596. doi:10.1007/ s00586-015-3899-9

52. Phan K, Mobbs RJ. Evolution of Design of Interbody Cages for Anterior Lumbar Interbody Fusion. Orthop Surg. 2016;8 (3):270-277. doi:10.1111/os.12259

53. Patel DV, Yoo JS, Karmarkar SS, Lamoutte EH, Singh K. Interbody options in lumbar fusion. $J$ Spine Surg. 2019;5(Suppl 1):S19-S24. doi:10.21037/jss.2019.04.04

54. Au AG, Aiyangar AK, Anderson Pa, Ploeg HL. Replicating interbody device subsidence with lumbar vertebraesurrogates. Proc Inst Mech Eng H. 2011;225(10):972-985. doi:10.1177/0954411911 415198
55. Au AG, Aiyangar AK, Anderson PA, Ploeg HL. A new bone surrogate model for testing interbody device subsidence. Spine. 2011;36 (16):1289-1296. doi:10.1097/BRS.0b013e31820bffe9

56. Hsu CC. Shape optimization for the subsidence resistance of an interbody device using simulation-based genetic algorithms and experimental validation. J Orthop Res. 2013;31(7):1158-1163. doi: $10.1002 /$ jor.22317

57. Ji H, Xie X, Zhuang S, Zhang C, Xie L, Wu X. Comparative analysis of three types of titanium mesh cages for anterior cervical single-level corpectomy and fusion in term of postoperative subsidence. Am J Transl Res. 2020;12(10):6569-6577.

58. Jost B, Cripton PA, Lund T, et al. Compressive strength of interbody cages in the lumbar spine: the effect of cage shape, posterior instrumentation and bone density. Eur Spine J. 1998;7(2):132-141. doi: $10.1007 / \mathrm{s} 005860050043$

59. Tan JS, Bailey CS, Dvorak MF, Fisher CG, Oxland TR. Interbody device shape and size are important to strengthen the vertebra-implant interface. Spine. 2005;30(6):638-644. doi:10.1097/ 01.brs.0000155419.24198.35

60. Choy WJ, Parr WCH, Phan K, Walsh WR, Mobbs RJ. 3-dimensional printing for anterior cervical surgery: a review. J Spine Surg. 2018;4 (4):757-769. doi:10.21037/jss.2018.12.01

61. Collino R, Kiapiour A, Begley M. Subsidence of 3D-Printed Cages in Foam Substrates: effect of Contact Topology. J Biomech Eng. 2020;142. doi:10.1115/1.4046584

62. Murr LE, Gaytan SM, Medina F, et al. Next-generation biomedical implants using additive manufacturing of complex, cellular and functional mesh arrays. Philos Trans a Math Phys Eng Sci. 2010;368 (1917):1999-2032. doi:10.1098/rsta.2010.0010

63. Kivell TL. A review of trabecular bone functional adaptation: what have we learned from trabecular analyses in extant hominoids and what can we apply to fossils? J Anat. 2016;228(4):569-594. doi:10.1111/joa.12446

64. Wang Y, Bi W. The truss structure of cancellous bone. Morphological basis of the function of load transmission of the synovial joint. Chin Med J. 1995;108(1):20-23.

65. Deligianni DD, Katsala N, Ladas S, Sotiropoulou D, Amedee J, Missirlis YF. Effect of surface roughness of the titanium alloy Ti-6Al-4V on human bone marrow cell response and on protein adsorption. Biomaterials. 2001;22(11):1241-1251. doi:10.1016/ S0142-9612(00)00274-X

66. Fujibayashi S, Takemoto M, Neo M, et al. A novel synthetic material for spinal fusion: a prospective clinical trial of porous bioactive titanium metal for lumbar interbody fusion. Eur Spine J. 2011;20 (9):1486-1495.

67. Gittens RA, McLachlan T, Olivares-Navarrete R, et al. The effects of combined micron-/submicron-scale surface roughness and nanoscale features on cell proliferation and differentiation. Biomaterials. 2011;32(13):3395-3403. doi:10.1016/j.biomaterials.2011.01.029

68. Korovessis PG, Deligianni DD. Role of surface roughness of titanium versus hydroxyapatite on human bone marrow cells response. $J$ Spinal Disord Tech. 2002;15(2):175-183; discussion 183. doi:10.1097/00024720-200204000-00015

69. Liu Y, Rath B, Tingart M, Eschweiler J. Role of implants surface modification in osseointegration: a systematic review. $J$ Biomed Mater Res A. 2020;108(3):470-484.

70. Martin JY, Schwartz Z, Hummert TW, et al. Effect of titanium surface roughness on proliferation, differentiation, and protein synthesis of human osteoblast-like cells (MG63). J Biomed Mater Res. 1995;29 (3):389-401. doi:10.1002/jbm.820290314 


\section{Publish your work in this journal}

Orthopedic Research and Reviews is an international, peer-reviewed, open access journal that focusing on the patho-physiology of the musculoskeletal system, trauma, surgery and other corrective interventions to restore mobility and function. Advances in new technologies, materials, techniques and pharmacological agents are particularly welcome. The manuscript management system is completely online and includes a very quick and fair peer-review system, which is all easy to use. Visit http://www.dovepress.com/testimonials.php to read real quotes from published authors.

Submit your manuscript here: https://www.dovepress.com/orthopedic-research-and-reviews-journal 